\title{
A Study of Changes in Risk-taking and Sociability in Chinese University EFL Class
}

\author{
Wenxia Zhang \\ Department of Foreign Languages and Literatures, Tsinghua University, Beijing, 100084, China \\ Email: wxzhang@mail.tsinghua.edu.cn \\ Meihua Liu \\ Department of Foreign Languages and Literatures, Tsinghua University, Beijing, 100084, China \\ Email: ellenlmh@gmail.com
}

\begin{abstract}
This paper reports the results of a study of changes in risk-taking and sociability in Chinese university EFL class over a term. A 10-item survey involving 934 first-year undergraduates revealed that: (1) the students generally did not like to risk using English and were moderately sociable in English class both at the beginning and toward the end of the term; (2) the participants became significantly more risk-taking in English class over the term; (3) male students reported being significantly more risk-taking than their female counterparts both at the beginning and toward the end of the term; and (4) language class risk-taking and sociability were significantly correlated with each other and the students' performance in English both at the beginning and toward the end of the term. As such, some implications for teaching and learning of English are discussed.
\end{abstract}

Index Terms - risk-taking, sociability, change

\section{INTRODUCTION}

The classroom is a crucial place for student interpersonal and educational development (Pierce, 1994). For years, researchers and educators have been interested in the relationship between students' classroom participation and their academic achievement, which shows that students who participate actively in class tend to achieve higher than those who are passive in class (Ely, 1986; Liu \& Jackson, 2008; McDonough, 2004; Spada, 1986). As Krupa-Kwiatkowski (1998, p. 133) claimed that 'interaction involves participation, personal engagement, and the taking of initiative in some way, activities that in turn are hypothesized to trigger cognitive processes conducive to language learning'. Since oral participation is the most observable behavior, much research has focused on this and its relationship with students' English proficiency or performance (Ely, 1986; Tsou, 2005).

In various language learning contexts, learners have been observed to be quiet in language classrooms, rarely responding to teachers' questions, or actively taking part in classroom discussions (Cortazzi \& Jin, 1996; Jackson, 2002; Tsui, 1996; Zou, 2004). Asian learners are especially often viewed as being passive, lacking initiative, and rarely volunteering answers (Liu, 2006; Liu \& Jackson, 2009; Saito \& Ebsworth, 2004; Tsui, 1996; Zou, 2004). As to gender difference in faculty-student interactions, mixed findings were revealed. For instance, Krupnick (1985) found that male students interacted more with their instructors than female students. Canada and Pringle (1995) found that female students initiated more faculty-student interactions than male students within mixed-sex classrooms, which was supported by the subsequent research done by Lin and Rancer (2003). Nevertheless, Brady and Eisler's (1999) study of 24 classes from various disciplines at a major university in America showed that men and women did not differ significantly in terms of their behaviors and interactions with faculty members, and that male-dominated classrooms were rated significantly less interactive than female-dominated and nondominated classrooms. The researchers also found that instructor monitoring of equity was the strongest predictor of an interactive classroom.

As English is becoming increasingly more important in China, and as the confidence of many Chinese people has been tremendously boosted up in recent years, it is assumed that Chinese EFL learners, especially university learners should be more enthusiastic, open-minded and active to learn and use English both in and outside class. Presumably, they should tend to be more risk-taking and sociable in English class. To confirm this assumption, the present study explored the changes in risk-taking and sociability in English class in relation to their relationships with the students' performance in English with a sample selected from three universities in China. And the research questions are: 1) Is there any change in language class risk-taking and sociability in university EFL class over the term? 2) Is there any difference in language class risk-taking and sociability between male and female students? and 3) How are language class risk-taking and sociability related to students' performance in English

\section{DESIGN}


934 (587 male and 347 female) first-year non-English majors from various disciplines in three Chinese universities participated in the present study. With an age range from 13 to 21 and an average age of 18.49, they all were enrolled in credit-bearing and compulsory English courses offered by their universities. They completed the 6-item Language Class Risk-taking (LCR) (Liu \& Jackson, 2008), the 4-item Language Class Sociability (LCS) (Liu \& Jackson, 2008), and the background questionnaire in around 7 minutes in class in the third (phase 1) and fourteenth (phase 2) week of a term. The LCR aimed to measure to what extent learners would risk using the target language in class. It was believed that learners who risked using the target language more often were more willing to communicate with others in class or vice versa (Ely, 1986). It achieved a reliability score of .60 and .629 in phases 1 and 2 respectively in the present research. The LCS intended to tap to what extent learners enjoyed interacting with others in the target language in class. It achieved a reliability score of .756 and .684 in phases 1 and 2 respectively in the present research. All the items except the background questionnaire were placed on a 5-point Likert scale ranging from "Strongly Disagree" to "Strongly Agree" with values 1-5 assigned to them respectively.

The data were analyzed in terms of mean and standard deviation to determine the general pattern of the students' language class risk-taking and sociability. $\mathrm{t}$-tests were run to explore the difference in language class risk-taking and sociability between male and female students and over the term. Finally, correlational analyses were conducted to reveal how the measured variables were related to the students' performance in English.

\section{RESULTS AND DISCUSSION}

\section{A. General Pattern of and Changes in Language Class Risk-taking and Sociability}

To reveal the general tendency of the students' language class risk-taking and sociability, the means and standard deviations of the LCR and the LCS in both phases were computed. The higher the score, the more risk-taking or sociable the respondent was in English classrooms. The results are shown in Table 1.

TABLE 1:

STATISTICAL ANALYSES OF THE LCR AND LCS (N = 934)

\begin{tabular}{|c|c|c|c|c|}
\hline \multicolumn{5}{|c|}{ STATISTICAL ANALYSES OF THE LCR AND LCS $(\mathrm{N}=934)$} \\
\hline & \multicolumn{2}{|l|}{ LCR } & \multicolumn{2}{|l|}{ LCS } \\
\hline & Phase 1 & Phase 2 & Phase 1 & Phase 2 \\
\hline Mean & 16.40 & 16.95 & 13.09 & 13.14 \\
\hline Standard Deviation & 3.72 & 3.63 & 2.82 & 2.76 \\
\hline
\end{tabular}

Since each item of the LCR and the LCS had five descriptors with values of 1 to 5 assigned to them respectively, a mean of $16.40(\mathrm{SD}=3.72)$ in phase 1 and $16.95(\mathrm{SD}=3.63)$ in phase 2 on the LCR, both below the scale midpoint 18 , reflects that the majority of the participants were moderately or even not risk-taking in both phases. Likewise, a mean of $13.09(\mathrm{SD}=2.82)$ in phase 1 and $13.14(\mathrm{SD}=13.14)$ in phase 2 on the LCS, all exceeding the scale midpoint 12 , suggests that the participants were moderately or even strongly sociable in English classrooms in both phases. All these findings were consistent with those revealed in Liu and Jackson's (2008) study of a sample with similar backgrounds.

Further, as noted from Table 1, the students generally tended to score higher on the LCR and the LCS in phase 2, implying that they became more risk-taking and sociable toward the end of the term. And the paired samples t-test results show that the difference in the LCR $(\mathrm{t}=-4.713, \mathrm{p}=.000)$ was statistically significant but that for the LCS $(\mathrm{t}=$ $-.549, \mathrm{p}=.583$ ) was statistically insignificant. Namely, the participants became significantly more risk-taking in English class over the term.

Gender differences in class risk-taking and sociability

To explore gender differences in language class risk-taking and sociability required the computation of the means and standard deviations of the LCR and the LCS for both males and females in the two phases (see Table 2).

TABLE 2:

GENDER DIFFERENCES IN THE LCR AND THE LCS

\begin{tabular}{|l|l|l|l|l|l|}
\hline \multirow{2}{*}{\multicolumn{2}{c|}{}} & Mean & \multicolumn{2}{l|}{ Standard Deviation } \\
\cline { 3 - 6 } \multicolumn{2}{c|}{ LCR } & Male & Female & Male & Female \\
\cline { 2 - 6 } & Phase 1 & 16.77 & 15.77 & 3.70 & 3.69 \\
\hline \multirow{2}{*}{ LCS } & Phase 2 & 17.15 & 16.62 & 3.61 & 3.65 \\
\cline { 2 - 6 } & Phase 1 & 13.01 & 13.21 & 2.80 & 2.86 \\
\hline
\end{tabular}

According to Table 2, males scored $16.77(\mathrm{SD}=3.70)$ in phase 1 and $17.15(\mathrm{SD}=3.61)$ in phase 2 on the LCR; and females scored $15.77(\mathrm{SD}=3.69)$ in phase 1 and $16.62(\mathrm{SD}=3.65)$ in phase 2 on the LCR, suggesting that both males and females generally did not like to risk using the target language in English class both at the beginning and toward the end of the term. Similarly, males scored $13.01(\mathrm{SD}=2.80)$ in phase 1 and $13.13(\mathrm{SD}=2.76)$ in phase 2 on the LCS; and females scored 13.21 ( $\mathrm{SD}=2.86)$ in phase 1 and $13.16(\mathrm{SD}=2.78)$ in phase 2 on the LCS, indicating that both were moderately or even strongly sociable in English class both at the beginning and toward the end of the term.

Moreover, comparison of male and female scores on both scales reveals that males scored higher than their female peers on the LCR but lower on the LCS in both phases. It seems that male students were more risk-taking than females both at the beginning and toward the end of the term, which might be related to the Chinese culture which respects men 
more (Bond, 1996; Scollon \& Scollon, 2000). Meanwhile, they reported to be less sociable than their female counterparts both at the beginning and toward the end of the term, consistent with a number of existing studies (Canada \& Pringle, 1995; Lin \& Rancer, 2003). Nevertheless, statistically significant difference was observed only in the LCR in both phases $(\mathrm{t}=3.99, \mathrm{p}=.000$; and $\mathrm{t}=2.16, \mathrm{p}=.03$ for phases $1 \& 2$ respectively), as supported by the independent samples t-test results. Alternatively, male students reported being significantly more risk-taking than their female counterparts both at the beginning and toward the end of the term.

\section{B. Correlations between Language Class Risk-taking and Sociability and Students'Performance in English}

Correlational analyses were conducted to explore the relationships between the students' language class risk-taking and sociability and their performance in English. The results are presented in Table 3.

TABLE 3:

CORRELATIONS BETWEEN LANGUAGE ClASS RISK-TAKING AND SOCIABILITY AND PERFORMANCE IN ENGLISH

\begin{tabular}{|l|l|l|l|}
\hline \multicolumn{2}{|c|}{ Performance } & LCR & LCS \\
\cline { 2 - 4 } & Phase 1 & $.168^{* *}$ & $.160^{* *}$ \\
\cline { 2 - 3 } & Phase 2 & $.070^{*}$ & $.155^{* *}$ \\
\hline
\end{tabular}

As noted in Table 3, both the LCR and the LCS were significantly positively correlated with the students' performance in English in both phases, with coefficients ranging from .070 to $.168(\mathrm{p}<.05)$. Alternatively, the more risk-taking and/or sociable a student reported to be in language class, the better she/he performed in English, as found in Ely (1986) and Liu (2009). Though the coefficients were not high, they did suggest that language class risk-taking and sociability affected students' performance in English and that they might interact with other variables to exert an effect on the latter.

In addition, correlational analyses demonstrate that the LCR was significantly positively correlated to the LCR in both phases $(r=.226$ and .123 respectively, $\mathrm{p}<.01)$. Namely, the more risk-taking a student reported to be in language class, the more sociable she/he was as well.

\section{CONCLUSIONS AND IMPLICATIONS}

Several conclusions can be drawn from the results of this study of Chinese university students' risk-taking and sociability in relation to their performance in English.

Analyses of the data revealed that the majority of the participants were moderately or even not risk-taking, and moderately or even strongly sociable in English classrooms both at the beginning and toward the end of the term. Toward the end of the term, the students became significantly more risk-taking in English class. Meantime, male students reported being significantly more risk-taking than their female counterparts both at the beginning and toward the end of the term, but no significant gender difference occurred in language class sociability in both phases. Finally, language class risk-taking and sociability were exposed to be significantly positively correlated with each other and the students' performance in English both at the beginning and toward the end of the term.

As such, it is beneficial to create a relaxing and non-threatening classroom environment to increase classroom risk-taking and participation, as suggested in several studies (Jackson, 2002; Liu, 2006; Tsui, 1996). A number of studies also suggest that it is conducive to creating a cohesive group and relaxing classroom environment if the EFL teacher acts as a facilitator who is characterized by empathic ability, acceptance of the members and congruence (Dallimore, Hertenstein \& Platt, 2004; Dörnyei \& Malderrz, 1997; Tsou, 2005). Thus, the learners' learning motivation can be enhanced, which leads to success in the FL classroom. Karabenick and Sharma's (1994) study of 25,000 American undergraduates of various disciplines showed that students who perceived their teachers as more supportive of classroom questioning were more likely to ask questions. Thus, the researchers suggested that teachers should well support their students. Tsou's (2005) study exposed that participation instruction was conductive to increasing student participation in interpersonal interactions in class, especially for those who came from traditional passive, teacher-centered classrooms, since it helped create a non-threatening, supportive and friendly classroom environment.

In addition, as students adapt more to the learning environment (e.g., classmates and teachers, the teaching style, more use of the target language), they become more willing to participate in interpersonal interactions and more active contributors to classroom activities, as found in existing studies (Liu, 2006; Liu \& Littlewood, 1997). Thus, it is helpful to increase the students' exposure to and access to the target language both in and outside class.

Finally, as found in Brady and Eisler's (1999) study, if instructors can be equitable to both male and female students, the class may become more interactive since each one's contribution to classroom discussions is equally valued.

\section{ACKNOWLEDGEMENT}

The present study was sponsored by Asia Research Center in Tsinghua University in 2010. 
[1] Bond, M. H. (1996). The Handbook of Chinese Psychology. Oxford: Oxford University Press.

[2] Brady, K. L., \& Eisler, R. M. (1999). Sex and gender in the college classroom: a quantitative analysis of faculty-student interactions and perceptions. Journal of Educational Psychology, 91, 127-145.

[3] Canada, K., \& Pringle, R. (1995). The role of gender in college classroom interactions: a social context approach. Sociology of Education, 68, 161-186.

[4] Cortazzi, M., \& Jin, L. (1996). Cultures of learning: language classrooms in China. In H. Coleman (ed.), Society and the Language Classroom (pp.169-206). Cambridge: Cambridge University Press.

[5] Dallimore, E. J., Hertenstein, J. H., \& Platt, M. B. (2004). Classroom participation and discussion effectiveness: student-generated strategies. Communication Education, 53, 103-115.

[6] Dörnyei, Z., \& Malderrz, A. (1997). Group dynamics and foreign language teaching. System, 25, 65-81.

[7] Ely, C. M. (1986). An analysis of discomfort, risk-taking, sociability, and motivation in the L2 classroom. Language Learning, $36,1-25$.

[8] Jackson, J. (2002). Reticence in second language case discussions: anxiety and aspirations. System, 30, 65-84.

[9] Karabenick, S. A., \& Sharma, R. (1994). Perceived teacher support of student questioning in the college classrooms: its relation to student characteristics and role in the classroom questioning process. Journal of Educational Psychology, 86, 90-103.

[10] Krupa-Kwiatkowski, M. (1998). "You shouldn't have brought me here!": interaction strategies in the silent period of an inner-direct second language learner. Research on Language and Social Interaction, 31, 133-175.

[11] Krupnick, C. G. (1985). Women and men in the classroom: inequality and its remedies. In M. M. Gullette (ed.), On Teaching and Learning (pp. 18-25). Cambridge, MA: Harvard-Danforth Center for Teaching and Learning.

[12] Lin, Y., \& Rancer, A. S. (2003). Sex differences in intercultural communication apprehension, ethnocentrism, and intercultural willingness to communicate. Psychological Reports, 92, 195-200.

[13] Liu, M. (2006). Reticence in oral English classrooms: causes and consequences. Asian Journal of English Language Teaching, $16,45-66$

[14] Liu, M. (2009). Reticence and Anxiety in Oral English Lessons. Berne: Peter Lang AG.

[15] Liu, M., \& Jackson, J. (2008). An Exploration of Chinese EFL Learners' Unwillingness to Communicate and Foreign Language Anxiety. The Modern Language Journal, 92, 71-86.

[16] Liu, M., \& Jackson, J. (2009). Reticence in Chinese EFL students with varied proficiency levels. TESL Canada Journal, 26, 65-81.

[17] Liu, N., \& Littlewood, W. (1997). Why do many students appear reluctant to participate in classroom learning discourse? System, 25, 371-384.

[18] McDonough, K. (2004). Learner-learner interaction during pair and small group activities in a Thai EFL context. System, 32, 207-224.

[19] Pierce, C. (1994). Importance of classroom climate for at-risk learners. Journal of Educational Research, 88, 37-42

[20] Saito, H., \& Ebsworth, M. E. (2004). Seeing English language teaching and learning through the eyes of Japanese EFL and ESL students. Foreign Language Annals, 37, 111-124.

[21] Scollon, R. \& Scollon, S. (2000). Intercultural Communication. Beijing: Foreign Language Teaching and Research Press.

[22] Spada, N. (1986). The interaction between types of contact and types on instruction: some effects on the second language proficiency of adult learners. SSLA, 1, 181-199.

[23] Tsou, W. (2005). Improving speaking skills through instruction in oral classroom participation. Foreign Language Annals, 38 , 46-55.

[24] Tsui, A. B. M. (1996). Reticence and anxiety in second language learning. In K. M. Bailey \& D. Nunan (eds.), Voices from the Language Classroom (pp. 145-167). Cambridge: Cambridge University Press.

[25] Zou, M. (2004). EFL learners' perceptions of in-class relationships and their voluntary responses. In Y. Gao (ed.), The Social Psychology of English Learning by Chinese College Students (pp. 149-167). Beijing: Foreign Language Teaching and Research Press.

Wenxia Zhang is professor of English at the Department of Foreign Languages, Tsinghua University, China. Her major research interests include EFL teaching and learning, language testing and EFL writing.

Meihua Liu is associate professor of English at the Department of Foreign Languages, Tsinghua University, China. Her research interests mainly include EFL teaching and learning in the Chinese context, individual differences, anxiety and reticence, and EFL writing. 